\title{
Characterization of shale-fluid interaction through a series of immersion tests and rheological studies
}

\author{
Samyukta Koteeswaran ${ }^{1} \cdot$ Mehdi Habibpour $^{1} \cdot \operatorname{Jim}$ Puckette $^{2} \cdot$ Jack C. Pashin $^{2} \cdot$ Peter E. Clark $^{1}$
}

Received: 16 February 2017 / Accepted: 6 February 2018 / Published online: 17 February 2018

(c) The Author(s) 2018. This article is an open access publication

\begin{abstract}
This paper presents qualitative techniques for evaluating shale-fluid interaction. Undesirable shale-fluid interactions lead to wellbore instability, formation damage and other problems that cost the petroleum industry millions of dollars annually. A simple desktop test method, such as immersion testing, can help production engineers choose the appropriate shale inhibitors such as salt, tetramethylammonium chloride (TMAC) and polymers that can effectively reduce the impact of oilfield fluids invading shale and causing it to swell or disperse. The swelling tendency of shale is highly dependent on clay mineralogy and other properties, such as porosity and permeability. A series of immersions tests was performed to study the combined and isolated effects of salt, TMAC, and polyacrylamide on preventing shale from becoming unstable. The merit of each fluid system in shale inhibition is probed for Woodford, Chattanooga and Pride Mountain shale. Rheology of bentonite slurries is studied with different salts and TMAC to probe their efficiency in preventing the swelling of bentonite clay. Additionally, rheology of bentonite with anionic and cationic polyacrylamide and salt is investigated.
\end{abstract}

Keywords Immersion tests $\cdot$ Salts $\cdot$ TMAC $\cdot$ Bentonite $\cdot$ Shale inhibition $\cdot$ Polyacrylamide

\section{Introduction}

The interaction of shales with fluids used in drilling, completion, and stimulation of shale formations is an important and not well-understood aspect of the drilling, completion and production optimization process. Shale is a fine-grained sedimentary rock with high clay content (Huang et al. 1998). Clay minerals have a great influence on the chemical and mechanical stability of shale. The common clay minerals present in shale are illite, montmorillonite, smectite, calcite and kaolinite (Lu 1988). Each clay mineral when present in abundance significantly changes the shale properties. For instance, mixed layer illite-smectite-rich shale is reactive with water and smectite causes swelling of shale when in contact with water. Shale swelling is a primary cause of wellbore instability. When the shale absorbs water and ionic

Peter E. Clark

peter.clark@okstate.edu

1 School of Chemical Engineering, Oklahoma State University, 420 Engineering North, Stillwater, OK 74078, USA

2 Boone Pickens School of Geology, Oklahoma State University, Stillwater, OK 74078, USA compounds from the injected fluid, it causes the clay layers to expand and the rock to swell (Zhang et al. 2004). Among the most important phenomena that cause shale to swell are osmotic effects associated with interaction of wellbore fluid with natural pore fluid during drilling and completion, as well as physio-chemical interactions between the reactive components of shale and the surrounding fluid (Chenevert 1970; Steiger 1993; Zhang et al. 2004).

Recent research demonstrates that each shale formation behaves uniquely when contacted with injected fluids (Gomez and He 2012). Hence, formulations of these injected fluids have to be taken into account to minimize adverse effects. Interactivity between shale and wellbore fluid are measured by different means. Traditional tests, such as dispersion tests and swelling tests, do not fully account for the influence of fluid on rock structure and fracture development in shale (Zhou et al. 2013). Some of the commonly used methods use shale that is ground into fine particles and then reconstituted with water. These tests give completely different results that are often far from reality. Immersion tests give a visual confirmation of the effect of different types of fluid on rock structure (Rabe et al. 2002; Santos et al. 1997). Immersion tests are used to evaluate the suitability of different drilling fluids for a particular shale formation. However, 
the absence of the confining pressure is a major limitation to the method (Santos et al. 1997). In this study, the interaction of wellbore fluids with shale was studied as a function of polymer concentration and salt type and concentration.

Many studies have been performed in the past to study different mechanisms of shale-fluid interaction. Some of the most common and significant shale-fluid interaction mechanisms are as follows (Lal 1999; Van Oort 2003; Van Oort et al. 1995):

1. Darcy flow: Darcy flow is governed by the hydraulic gradient, and the water is driven into the shale when the wellbore pressure is greater than shale pore pressure.

2. Diffusive flow: Diffusive flow is governed by the chemical potential gradient between the ions in the shale and the ions present in the fluid that is in contact with the shale. The ion movement between the shale and the surrounding fluid is dependent on the activity of the fluid and cation exchange capacity of the shale. Higher water activity sets the diffusive flow of water out of the shale and vice versa. Additives such as salts are used to alter the water activity.

3. Osmotic flow: Osmotic flow plays a significant role in altering shale-fluid interaction. The direction of flow and the interactions that follow it is dependent on factors such as membrane efficiency of shale and water activity of injected fluids. The membrane efficiency of the shale is

$\sigma=\frac{\Delta P}{\Delta \pi}$

where $\sigma$ is the membrane efficiency, $\Delta P$ is pressure drop of the system, and $\Delta \pi$ is the osmotic potential. Where $\Delta \pi$ can be found using the following equation

$$
\Delta \pi=\left(\frac{R T}{V}\right) \ln \left(\frac{a_{\mathrm{w} 2}}{a_{\mathrm{w} 1}}\right)
$$

where $R$ is the universal gas constant, $T$ is the absolute temperature, $V$ is the partial molar volume of water, and $a_{\mathrm{w}}$ is the water activity. The water activity can be related to chemical potential using the following equation

$$
\mu=\mu_{i 0}+R T \ln a_{i}
$$

where $\mu_{i 0}$ is the chemical potential of pure component at standard conditions.

Adding salts can alter the water activity of the injected fluids, and using polymers to cause polymeric bridging between the clay platelets and preventing water and ions from invading the shale pore matrix can alter the membrane efficiency of the shale (Koteeswaran et al. 2017; Lu 1988).

The common additives used in oilfield operations are friction reducers, acids, gellants, crosslinkers, clay control agents and other polymers. Polyacrylamide polymers are the most commonly used friction reducers and are also used as shale inhibitors albeit at higher concentrations (Habibpour et al. 2017). High molecular weight polymers, such as polyacrylamide, provide effective shale inhibition by increasing the membrane efficiency of shale-they form a highly viscous isolation membrane on the shale that protects the rock from water (Mody et al. 2002). High molecular weight polyacrylamides also provide better friction reduction than the commonly used biopolymers such as guar and xanthan gum. High molecular weight polyacrylamides are thermally stable polymers that are stable at temperatures as high as $200{ }^{\circ} \mathrm{C}$ (Carman and Cawiezel 2007; Zhou et al. 2011).

Potassium chloride $(\mathrm{KCl})$, sodium chloride $(\mathrm{NaCl})$ and TMAC are some of the common additives that are used to mitigate reaction of clay with process water. Salts such as $\mathrm{NaCl}$ and $\mathrm{KCl}$ are widely used in injected fluids for stabilization. Potassium salts are used as clay-swelling inhibitors, because the potassium $\left(\mathrm{K}^{+}\right)$ions penetrate into the porosity of the shale, creating a semi-permeable membrane, which prevents the water from entering the shale (Khodja et al. 2010). Simplified exposure tests were performed by Horsrud et al. (1998) at simulated borehole conditions. They observed that exposure to $\mathrm{KCl}$ caused shrinkage of shale matrix and an increase in permeability. Shrinkage of shale is due to the $\mathrm{K}^{+}$ions replacing the previously adsorbed exchangeable cations on the clay surface leading to the compaction of clay structure (Horsrud et al. 1998; Okoro and Adewale 2014). The rate of water inflow into the shale formation decreases with salt concentration due to the chemical potential of the process fluid being lower than that of the formation. This eventually leads to slower rate of pore pressure increase, thereby increasing shale stability (Tan et al. 1996). Shale exposed to salt solutions, such as $\mathrm{KCl}, \mathrm{NaCl}$ and $\mathrm{CaCl}_{2}$, dehydrates by transport of pore water into the contacting fluid (Al-Bazali et al. 2008). Movement of ionic compounds from the shale to the fluid provides a reduction in intergranular friction that allows the grains to slip as stress is increased. This enhances shale strength (Al-Bazali et al. 2008; Tan et al. 1996). However, excessive dehydration can cause a decrease in the formation strength, thus reducing wellbore stability (Tan et al. 1996). $\mathrm{KCl}$ also offsets the friction reduction properties of polyacrylamide. Hence, the salt and polyacrylamide concentration should be carefully chosen to reduce viscosity reduction in polyacrylamides in the presence of salts.

Based on the immersion tests and rheological studies done in laboratory, recommendations are provided for the four shale under study for the polymer and salt use. Additionally, based on the rheological properties of the fluid mixtures used in this study an optimum salt and polyacrylamide system based on the rheological property of the fluid mixtures is determined. 


\section{Materials and methods}

\section{Experimental methods}

This section is divided into two subsections. The first part focuses on characterizing shale samples in terms of mineralogy, porosity, total organic carbon (TOC) content, and pressure decay permeability. The second section focuses on immersion testing and analysis of the rheological properties of shale-fluid slurries to analyze the sensitivity of shale to wellbore fluids.

\section{Shale samples}

To observe the effects of different wellbore fluid additives on shale, immersion testing was performed on shale samples from the Woodford Shale (Devonian, Anadarko Basin), Pride Mountain Formation (Mississippian, Black Warrior Basin), and Pottsville Formation (Pennsylvanian, Black Warrior Basin). Well-preserved core samples were used for the tests. Drying of the samples prior to the test causes a change in water content in the shale. A minimal change in water content dramatically changes the reactivity of the shale. Shale samples that were used in the tests were carefully preserved with large surface area that has had minimal exposure to coring fluids.

\section{Shale characterization}

To characterize shale-fluid interaction, it is imperative to characterize shale samples in terms of mineralogy, total organic carbon (TOC) content, porosity and fluid saturation, and permeability to help understand shale-fluid interactions. Table 1 shows the various characterization methods used for the study.

\section{Rock mineralogy}

$\mathrm{X}$-ray diffraction (XRD) is used to determine the clay and non-clay content present in the shale samples quantitatively. $\mathrm{XRD}$ is a robust and powerful technique widely used in the characterization of shales. The quantitative analysis of clay, non-clay and expandable clay content is done using XRD. Table 2 shows the clay content and the non-clay mineral content of the shale samples.

\section{Total organic content (TOC)}

The TOC is a crucial indicator of the development and behavior of shales. Many times TOC is determined in order to measure the kerogen content of the shale, but kerogen has sulfur, nitrogen, oxygen and hydrogen in addition to carbon. Organic rich shales have higher permeability and also are reactive compared to the less organic shales (Rickman et al. 2008). TOC, effective porosity and pressure decay permeability are shown in Table 3.

\section{Porosity}

Determining the porosity of shale is important in understanding the mechanical behavior of shale at different stresses and in understanding shale stability and failure limit (Josh et al. 2012). The permeability of the shale is dependent on the pore sizes, which controls the elasticity and mechanical strength of shales (Khodja et al. 2010). Effective porosity is shown in Table 3.

\section{Pressure decay permeability}

The pressure decay permeability method is standard for measuring permeability in shale and other nano- to microdarcy rocks. Pressure decay takes a fraction of the time required for steady-state methods (Jones 1997). Pressure decay permeability measurements are shown in Table 3.

\section{Scanning electron microscopy}

SEM techniques were used to study the surface properties and morphology of the shale under study. Cores were sliced to get 1-2 $\mathrm{mm}$ shale samples, parallel to the bedding plane. The sample was placed on the stub which was sputter-coated with conducting layers of gold. The surface of the shale was examined using different magnifications. In
Table 1 Shale characterization methods

\begin{tabular}{|c|c|c|}
\hline Measurement & Equipment & Determination \\
\hline Mineralogy & $\mathrm{X}$-ray diffraction & Percentage composition of clay and non-clay minerals \\
\hline TOC & & Organic content of shale \\
\hline Porosity and fluid saturation & & $\begin{array}{l}\text { Porosity of shale with respect to mobile pore fluid } \\
\text { volume (water, oil, gas) }\end{array}$ \\
\hline Pressure decay permeability & & Clay matrix permeability \\
\hline Surface characteristics & $\begin{array}{l}\text { Scanning electron } \\
\text { microscopy }\end{array}$ & Mineral fabric, surface morphology of shale \\
\hline
\end{tabular}


order to determine the elemental composition of shales, the shale samples were coated with layers of carbon and energydispersive spectroscopy (EDS) analysis of shale samples was done to determine elemental composition. Figures 1,2 and 3 show the morphology of the shale samples studies in this work.

\section{Formulation of fluid phase}

\section{Fluid design}

One of the main objectives of this study was to study shale-fluid interaction. The fluids used are common oilfield
Table 2 Whole rock mineralogy of shale samples from different formations
Table 3 TOC, effective porosity, pressure decay permeability and $\%$ water saturation
Fig. 1 SEM images of Woodford Shale in Rother $(10,372.1 \mathrm{ft}$.). Images a and b contain abundant randomly oriented clay platelets

\begin{tabular}{lllll}
\hline Analysis & Woodford & Woodford & Chattanooga & Pride Mountain \\
\hline Depth (ft.) & 10,372 & 10,382 & 9156.50 & 2863 \\
Clay content (wt.\%) & & & 0 & 1 \\
Smectite & 6 & 3 & 5 & 16 \\
Ilite/smectite & 33 & 28 & 24 & 37 \\
Ilite + Mica & $\operatorname{Tr}$ & $\operatorname{Tr}$ & 0 & 12 \\
Kaolinite & 1 & $\operatorname{Tr}$ & 0 & 4 \\
Chlorite & & & & \\
Non-clay mineral content (wt.\%) & 28 & 32 & 41 & 21 \\
Quartz & 5 & 4 & 16 & 3 \\
K Feldspar & 8 & 7 & 2 & 2 \\
Plagiocase & $\operatorname{Tr}$ & $\operatorname{Tr}$ & 0 & 1 \\
Calcite & 2 & 1 & 0 & 1 \\
Ankerite/Fe dolomite & & & 5 & 0 \\
Dolomite & 6 & 4 & 5 & 1 \\
Pyrite & $\operatorname{Tr}$ & 0 & 0 & 0 \\
Fluorapatite & 0 & 0 & 1 & 1 \\
Barite & $\operatorname{Tr}$ & 0 & 0 & 1 \\
Siderite & 0 & 0 & 0 \\
Magnetite & & 0 & & \\
\hline
\end{tabular}

\begin{tabular}{llllc}
\hline Parameters & $\begin{array}{l}\text { Woodford } \\
(10,372 \mathrm{ft} .)\end{array}$ & $\begin{array}{l}\text { Woodford } \\
(10,382 \mathrm{ft} .)\end{array}$ & $\begin{array}{l}\text { Chattanooga } \\
(9156.50 \mathrm{ft} .)\end{array}$ & $\begin{array}{l}\text { Pride Moun- } \\
\text { tain }(2863 \mathrm{ft} .)\end{array}$ \\
\hline TOC (wt.\%) & 4.68 & 3.76 & 3.33 & 0.80 \\
Effective porosity (\% of BV) & 4.8 & 4.8 & 2.32 & 12.30 \\
Pressure decay permeability $(\mu \mathrm{D})$ & 0.36 & 0.53 & 0.32 & 0.48 \\
Water saturation \% of PV & 40 & 29.7 & 8.13 & 76.56 \\
\hline
\end{tabular}

A

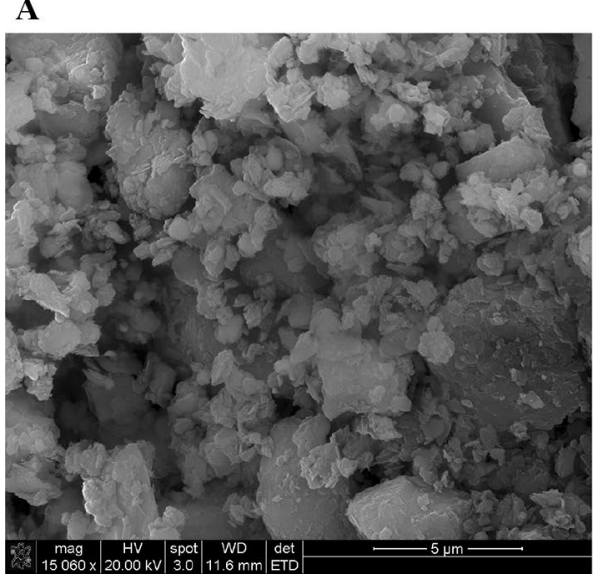

B

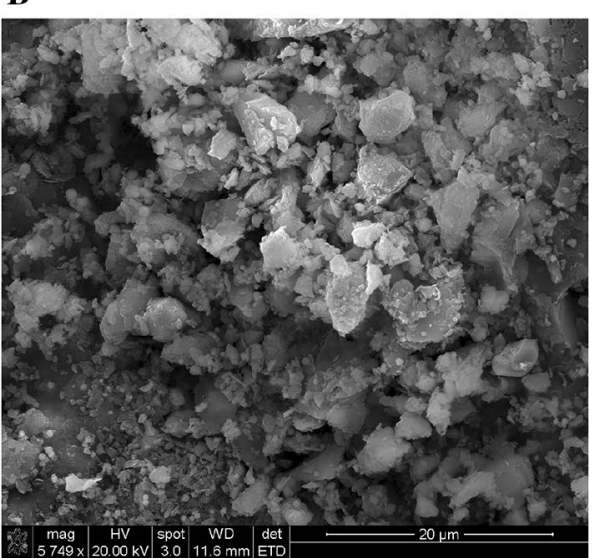


fluids combined with additives, such as anionic and cationic polyacrylamide. Wyoming bentonite was used as the clay in this study. Other additives include $\mathrm{KCl}, \mathrm{NaCl}$ and tetramethyl ammonium chloride (TMAC) (Table 4).

\section{Equipment}

A discover DHR-3 controlled stress rheometer was used to make rheological measurements of the samples. Vane geometry was used for the polymer-shale samples; this geometry helps prevent wall slippage at higher shear rates, helps disrupt flow inhomogeneity while shearing, and also works well for samples containing suspended solids. For polymer solutions, the cone and plate geometry was used. Cone and plate is useful for solutions that have low viscosity and do not contain suspended solids $>64 \mu \mathrm{m}$ in diameter. Cone and plate geometry (diameter: $60 \mathrm{~mm}$ and cone angle $2^{\circ}$ ) provides homogenous shear, shear rate and stress in the geometry gap. All experiments were performed at a temperature of $25{ }^{\circ} \mathrm{C} \pm 0.03{ }^{\circ} \mathrm{C}$. The polymer-shale sample was pre-sheared at $200 \mathrm{~s}^{-1}$ before the start of each experiment.
Fig. 2 SEM images of pyrite in the Gorgas \#1 well, Pride Mountain Formation (2864.4 ft.). a Poorly aligned and folded clay platelets. $\mathbf{b}$ Clusters of pyrite crystals forming of spherical to oblate framboids
A

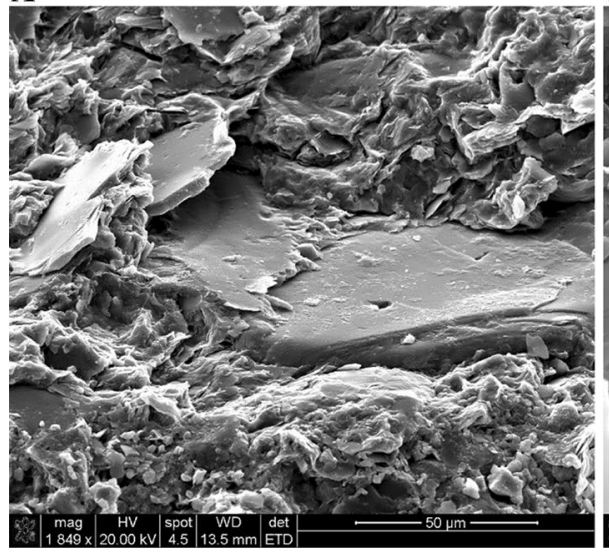

B

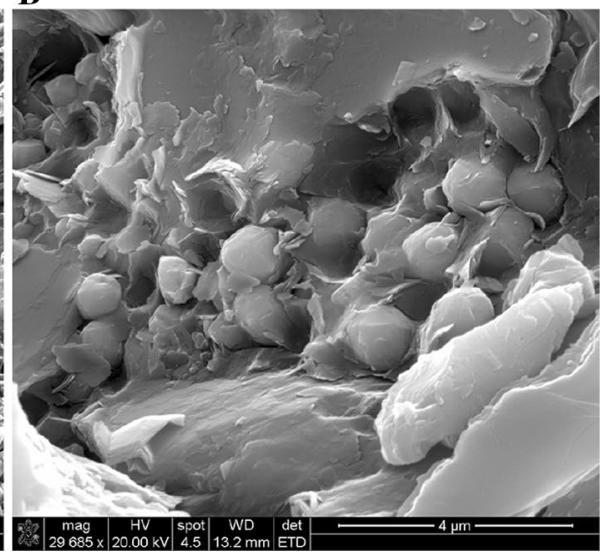

Fig. 3 SEM images of Chattanooga Shale in Lamb 1-3 \#1 well (9173.5 ft). a Randomly oriented clay platelets and $\mathbf{b}$ pyrite framboids in matrix of platy illite
Table 4 Composition of different fluid mixture used in the study
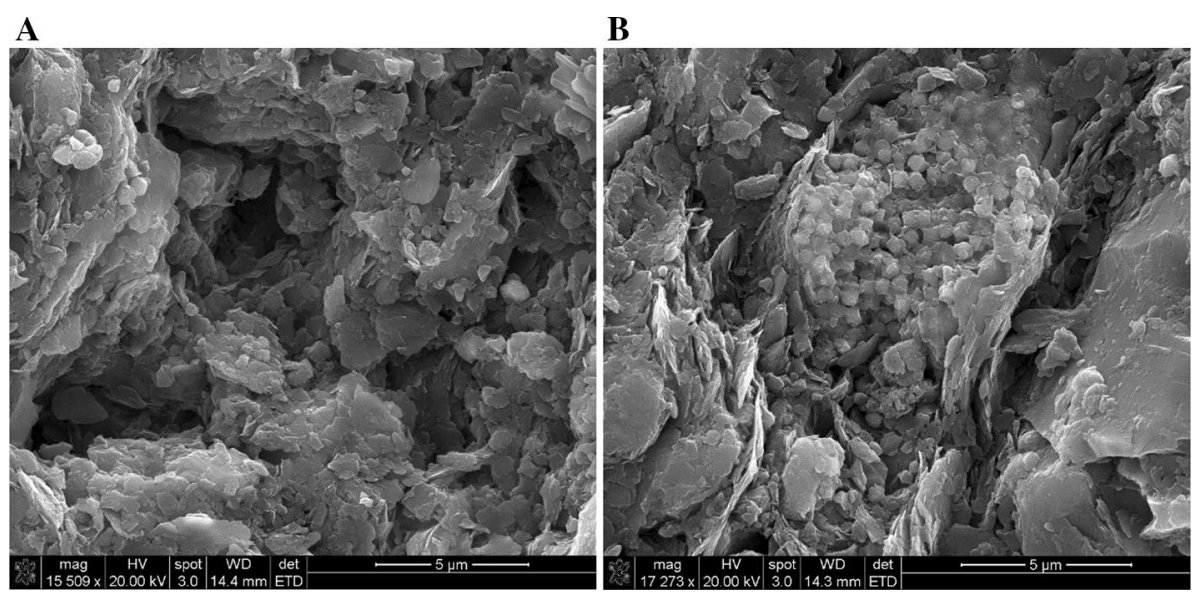

\begin{tabular}{lll}
\hline S. no. & Fluid mixture & Composition \\
\hline 1 & Bentonite & $2 \mathrm{lb} / \mathrm{bbl}$ bentonite $+0.2 \mathrm{wt} . \%$ anionic polyacrylamide \\
& $2 \mathrm{lb} / \mathrm{bbl}$ bentonite $+0.2 \mathrm{wt} \%$ cationic polyacrylamide \\
2 & $2 \mathrm{lb} / \mathrm{bbl}$ bentonite $+0.2 \mathrm{wt} \%$ anionic polyacrylamide $+2 \% \mathrm{KCl}$ \\
& $2 \mathrm{lb} / \mathrm{bbl}$ bentonite $+0.2 \mathrm{wt} . \%$ cationic polyacrylamide $+2 \% \mathrm{KCl}$ \\
3 & $2 \mathrm{lb} / \mathrm{bbl}$ bentonite $+0.2 \mathrm{wt} . \%$ anionic polyacrylamide $+2 \% \mathrm{NaCl}$ \\
& & $2 \mathrm{lb} / \mathrm{bbl}$ bentonite $+0.2 \mathrm{wt} \%$ cationic polyacrylamide $+2 \% \mathrm{NaCl}$ \\
4 & NaCl-bentonite & $2 \mathrm{lb} / \mathrm{bbl}$ bentonite $+0.2 \mathrm{wt} \%$ anionic polyacrylamide $+2 \% \mathrm{TMAC}$ \\
& & $2 \mathrm{lb} / \mathrm{bbl}$ bentonite $+0.2 \mathrm{wt} \%$ cationic polyacrylamide $+2 \%$ TMAC \\
\hline
\end{tabular}

Base fluid used is DI water (400 ml) 


\section{Immersion tests}

Preserved core samples were immersed in different fluid mixtures of varying compositions at $60{ }^{\circ} \mathrm{C}$. The samples were sealed and left in the fluid for 5 days for inert shale and 2 days for reactive shale. The change in weight of the shale samples before and after the test, linear swelling, and the change of hardness were measured. SEM images of the samples were taken after exposure to characterize morphologic changes on the shale surface. The change in thickness of shale samples used in study was measured before and after the immersion tests using a Vernier caliper. This provides a qualitative measurement of the extent of sample expansion or shrinkage when in contact with the injected fluids. Additionally, change in weight of the shale samples was measured after immersion tests. The results were correlated with the linear swelling test results. In order to study the isolated effect of salt and polyacrylamides separately, immersion tests were performed with salts, polyacrylamides, and no additives.

\section{Results and discussion}

The Woodford sample was immersed in salt solution to study the effectiveness of salt for preventing swelling. Figure 4 shows the percent expansion/shrinkage of Woodford Shale immersed in $\mathrm{KCl}, \mathrm{NaCl}$, TMAC and DI water. The shale swells most in DI water. This is expected due to the water activity being highest in DI water; the water is driven toward the shale, which causes the swelling. This result is reflected in weight gain where DI water has the maximum weight gain. In the absence of other additives, TMAC causes maximum shrinkage. In many cases, shrinkage of shale by dehydration increases rock strength, and hence, wellbore stability (Horsrud et al. 1998; Mody and Hale 1993; Zhang et al. 2004). However, in the previous studies, it has been shown that excessive shrinkage of shale can cause reduction in strength (Horsrud et al. 1998).

Figure 5 shows the percentage of expansion and shrinkage of Woodford Shale immersed in anionic polyacrylamide and cationic polyacrylamide in comparison with DI water. Shale immersed in anionic polyacrylamide shrinks more than the cationic polyacrylamide. When compared with salt solutions, the polyacrylamides provide better inhibition of swelling. Polymers have been proven to be effective in bridging the interlayer spacing between the clay platelets, and they also form a stable isolation membrane that prevents the water from entering the shale.

To study the effectiveness of salts, TMAC, and polyacrylamides as shale inhibitors when mixed with bentonite mud, immersion tests were performed with fluid mixtures as shown in Table 4. When in contact with the medium, all of the Woodford samples shrunk. Shrinkage was greater in TMAC, and minimal with $\mathrm{NaCl}$ and cationic polyacrylamide. However, the samples showed considerable weight gain because of adsorption of the polyacrylamides on the shale surface.

The effect of salts, TMAC and polyacrylamides on the swelling behavior of Woodford Shale was studied separately (Figs. 4, 5, 6, 7). As expected, the swelling was greatest for shale immersed in DI water. The shale immersed in a $2 \% \mathrm{NaCl}$ solution swelled, whereas it shrunk in a $2 \% \mathrm{KCl}$ solution. The hydrated radius of sodium is larger than that of potassium as a result of which a greater amount of water entered Woodford Shale after it was exposed to the $\mathrm{NaCl}$ solution (Zhou et al. 2013). Maximum weight gain was greatest for shale immersed in DI water followed by $2 \%$ $\mathrm{NaCl}, 2 \% \mathrm{KCl}$ and 2\% TMAC, respectively (Figs. 8, 9).

Bentonite mud is commonly used when drilling shale wells and is proven to cause swelling and dispersion of shale formations. But when used with polyacrylamides and salts,
Fig. 4 Percent expansion or shrinkage of Woodford Shale after immersion test

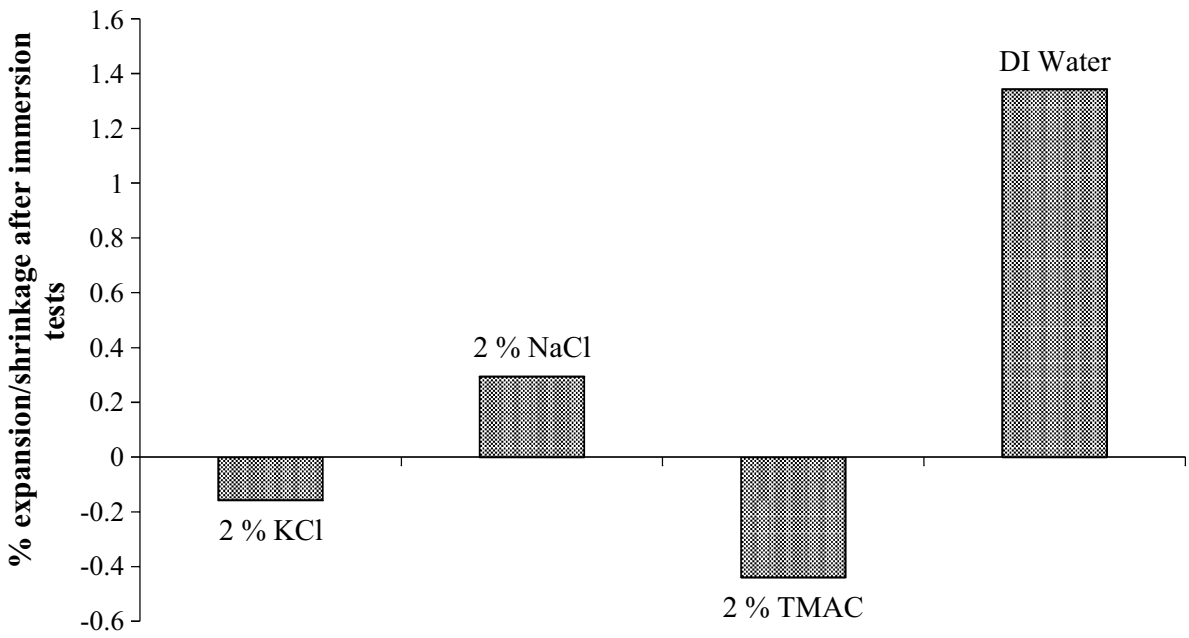

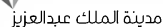
KACST: 
Fig. 5 Percent expansion or shrinkage of Woodford Shale after immersion test

Fig. 6 Percent expansion or shrinkage of Woodford Shale after immersion test

Fig. 7 Percent weight gain of Woodford Shale after immersion test
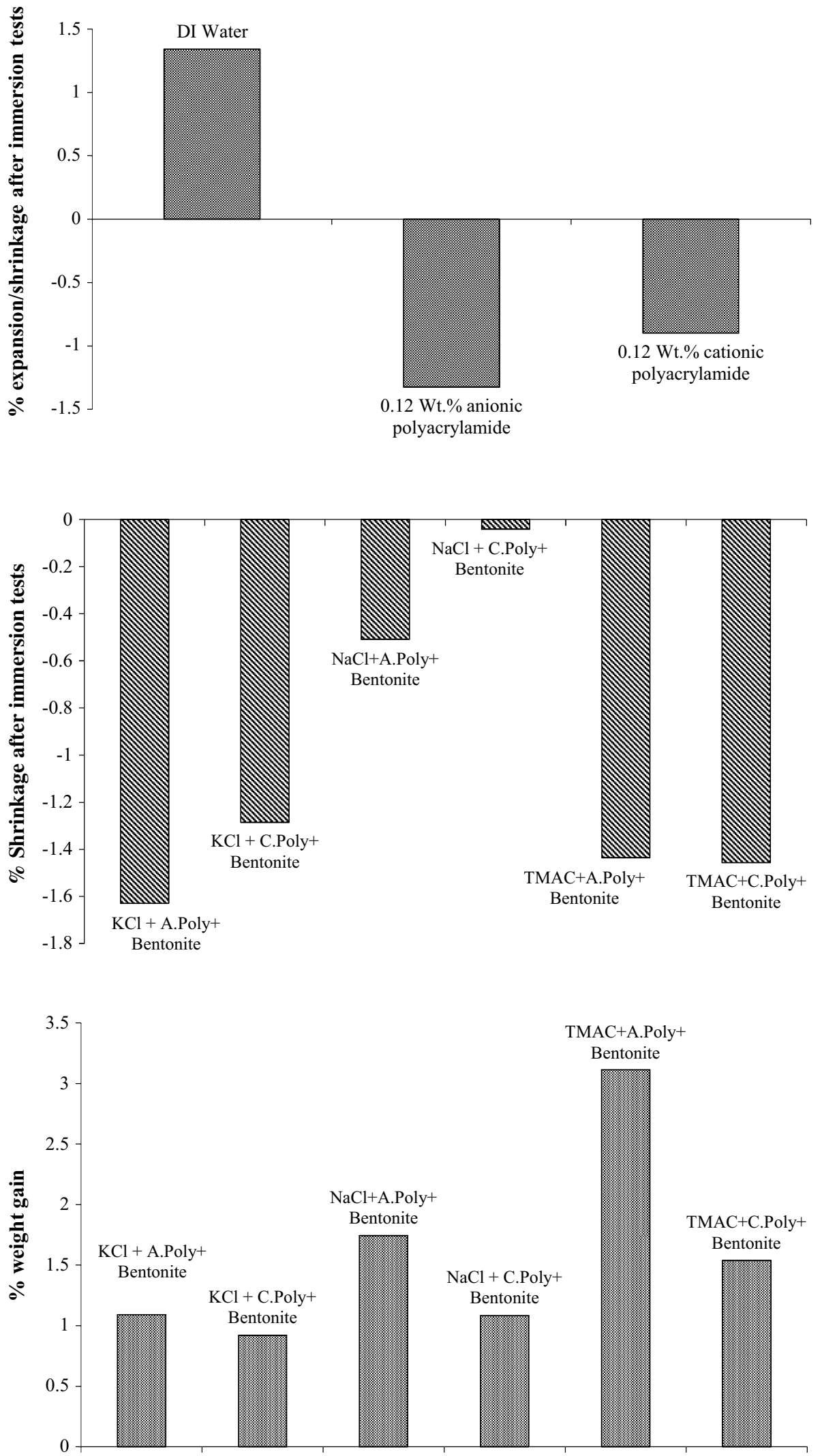
Fig. 8 Percent weight gain of Woodford Shale after immersion test
Fig. 9 Percent weight gain of Woodford Shale after immersion test
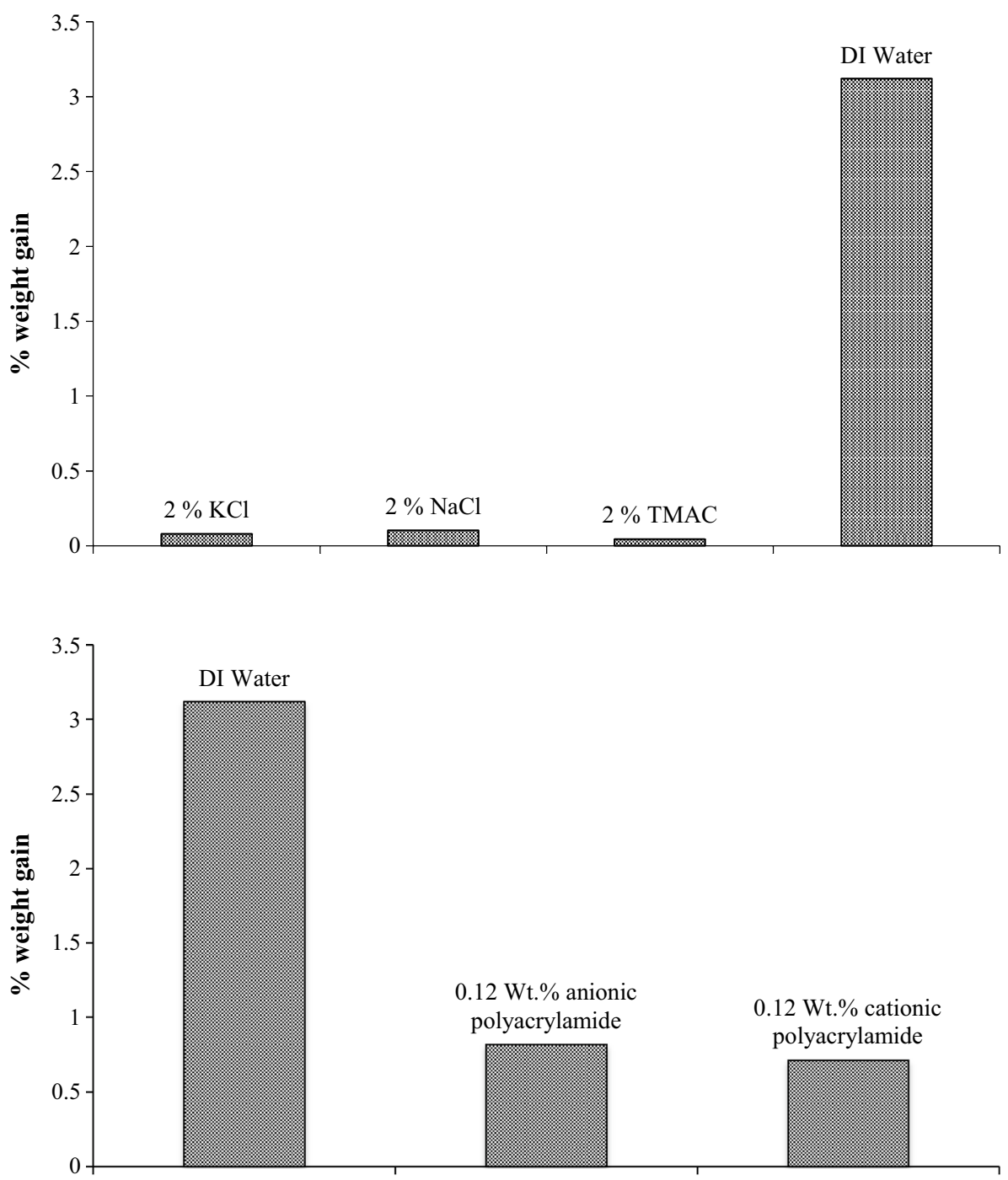

the swelling can be minimized. The mechanism of shale inhibition investigated in this study is effective adsorption of polyacrylamide and salt on the shale, which prevents water from entering the shale. The surface of immersed shale was analyzed using SEM to see the nature of polyacrylamide-salt adsorption (Fig. 10, 11, 12, 13).

There was a significant change in the surface morphology of shale immersed in mud systems 2, 3 and 4 as observed using SEM. Bentonite with $\mathrm{NaCl}$ and anionic polyacrylamide forms a uniform membrane over the shale, which prevents the water from entering or leaving the shale, which explains the small percentage of shrinkage. As seen in Fig. 11, there is minimal adsorption of polyacrylamide on the Woodford Shale surface. TMAC has proven to effectively inhibit polymers from adsorbing onto the shale surfaces from the fracturing fluids (Himes and Simon 1990). For shale immersed in cationic polyacrylamide with salts, salt and polyacrylamide precipitate on the surface of the shale. The $\mathrm{KCl}-$ cationic polyacrylamide system, in particular, provides a better inhibition due to the precipitation of salts on the surface which forms a thicker layer on the shale which prevents the shale from swelling or dispersing. The precipitation of the osmotic membrane on the exposed shale surface prevents the flow of water and ions into the shale; this membrane, however, allows water movement out of the shale, which leads to the shrinking of the shale (Fink 2015).

The qualitative description of Woodford Shale samples is shown in Table 5 after the immersion tests. For most of the tests the Woodford sample remained intact and did not disperse or disintegrate during the test period. This could be attributed to less expandable clay, which promotes swelling, and higher quartz content, which imparts mechanical strength. Additionally, low porosity reduces the reactivity of the shale. The shale was comparatively softer when immersed in TMAC-bentonite mud. There are two possible reasons for this phenomenon. First, TMAC prevents the adsorption of polyacrylamide on the surface of the shale that leads to water and ions entering and leaving the shale. The 


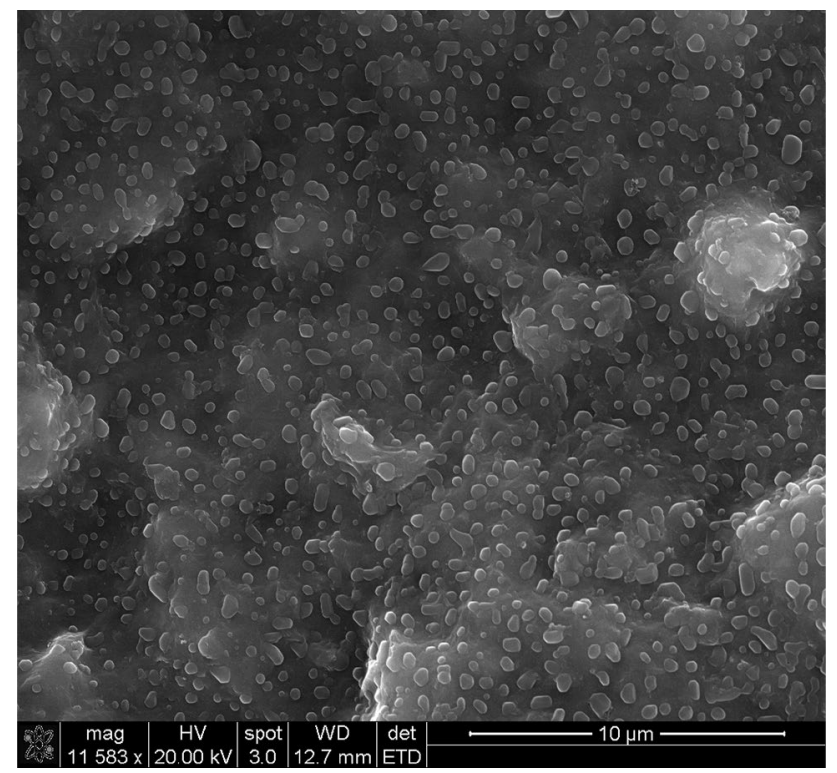

Fig. 10 Surface of Woodford Shale immersed in bentonite $+\mathrm{NaCl}+$ anionic polyacrylamide

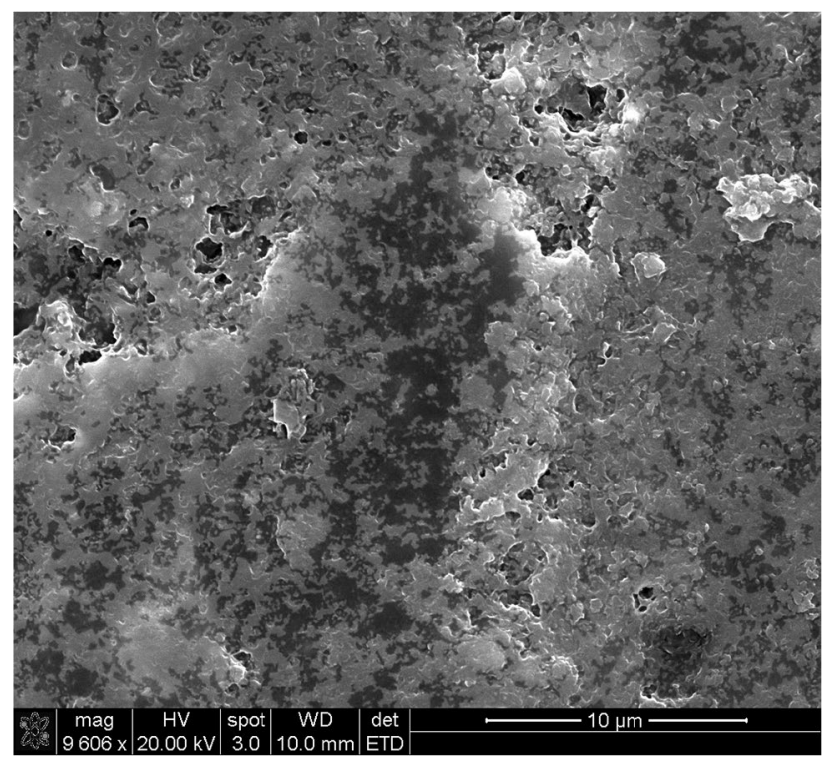

Fig. 11 Surface of Woodford Shale immersed in bentonite + TMAC + cationic polyacrylamide

second possibility is that the chemical potential difference between the fluid surrounding the shale and the pore fluid is higher, causing an osmotic potential difference that leads to shrinking of shale sample.

The Chattanooga and Pride Mountain shale samples were chosen to study the effect of salt and polyacrylamides for limiting the swelling/dispersion of shales. Chattanooga shale has a lower expandable clay and higher quartz content, which makes it hard. Conversely, Pride Mountain shale is

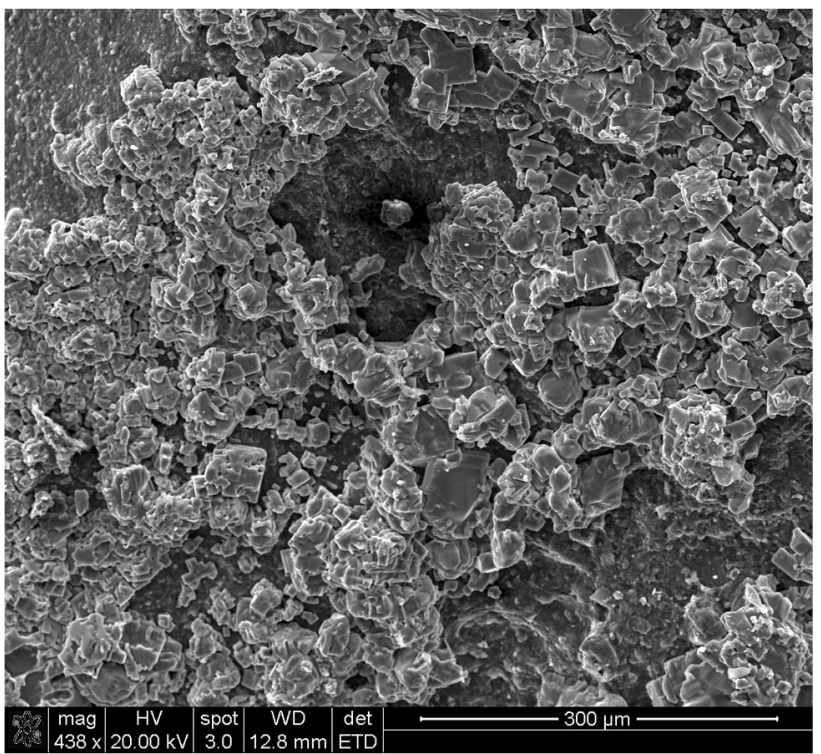

Fig. 12 Surface of Woodford Shale immersed in bentonite $+\mathrm{KCl}+$ cationic polyacrylamide

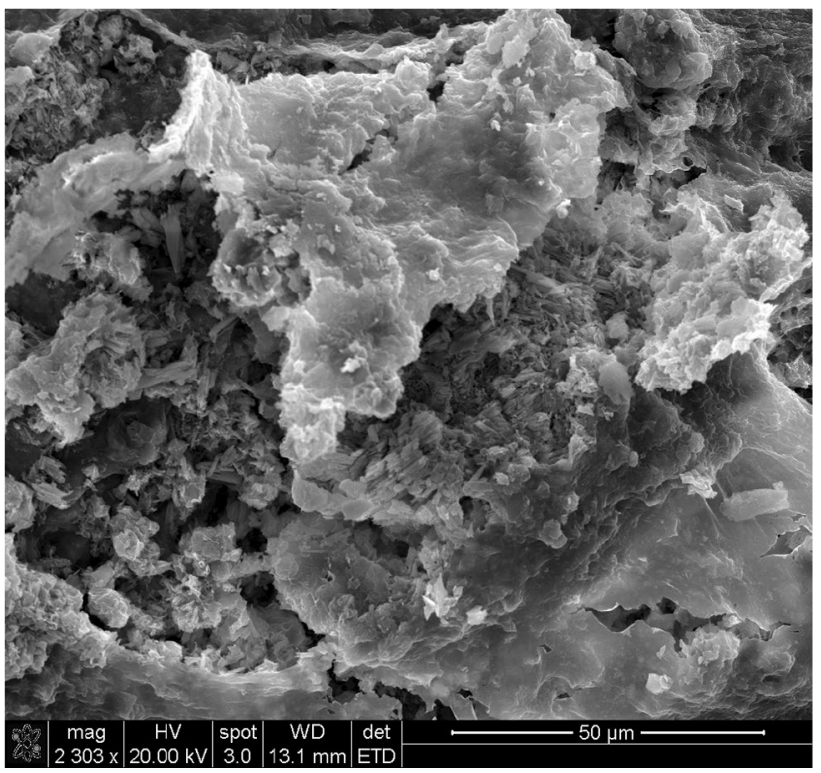

Fig. 13 Surface of Woodford Shale immersed in bentonite $+\mathrm{NaCl}+$ cationic polyacrylamide

rich in mixed and expandable clays and is soft. The change in weight of both the shales was used as a measure of shale reactivity (Fig. 14, 15, 16, 17). The weight gain was maximum for TMAC in Pride Mountain and Chattanooga shale, which is indicative of TMAC entering the shale and causing it to swell.

The transport of solutes to and from fluids to shales is caused by chemical potential gradient between the shale and the fluid (Van Oort 2003). The surrounding fluid's ion 
Table 5 Qualitative description of Woodford Shale samples after immersion tests

\begin{tabular}{ll}
\hline Sample & Qualitative description \\
\hline Anionic polyacrylamide + bentonite & Intact, soft \\
Cationic polyacrylamide + bentonite & Intact, firm \\
$\mathrm{KCl}+$ anionic polyacrylamide + bentonite & Intact, soft \\
$\mathrm{KCl}+$ cationic polyacrylamide + bentonite & Intact, hard \\
$\mathrm{NaCl}+$ anionic polyacrylamide + bentonite & Intact, hard \\
$\mathrm{NaCl}+$ cationic polyacrylamide + bentonite & Intact, hard \\
$\mathrm{TMAC}+$ anionic polyacrylamide + ben- & Intact, soft \\
tonite & \\
TMAC + cationic polyacrylamide + ben- & Intact, soft \\
tonite & Intact, hard \\
$2 \% \mathrm{KCl}$ & Intact, hard \\
$2 \% \mathrm{NaCl}$ & Intact, hard \\
$2 \% \mathrm{TMAC}$ & Intact, hard \\
$\mathrm{DI}$ water & Intact, hard \\
0.12 wt. $\%$ anionic polyacrylamide & Intact, hard \\
0.12 wt. $\%$ cationic polyacrylamide &
\end{tabular}

content exceeds that of the pore fluid that causes the ions to diffuse from the fluid to the shale. Also, ionic compounds in the interplatelet spaces cause swelling due to repulsion of ions of similar charge. TMAC in the absence of other additives adsorbs onto the shale surface, thereby causing repulsion of the $\mathrm{N}\left(\mathrm{CH}_{3}\right)_{4}^{+}$ions, which leads to an increase in swelling pressure. However, TMAC when used with other fluid additives such as polyacrylamides and bentonite can prove to be good at inhibiting swelling of the shale. It is recommended not to use high concentration of TMAC for Chattanooga and Pride Mountain shale even in the presence of other additives. The anionic and cationic polyacrylamides are efficient in preventing shale dispersion and swelling for both the Pride Mountain and Chattanooga shale. The qualitative description of the shale after the immersion tests is given in Tables 6 and 7. The recommendations for the type of salt to be used for the three shales are given in Tables 8 , 9 and 10.
Fig. 14 Percent weight gain of Chattanooga shale after immersion test

Fig. 15 Percent weight gain or loss of Chattanooga shale after immersion test
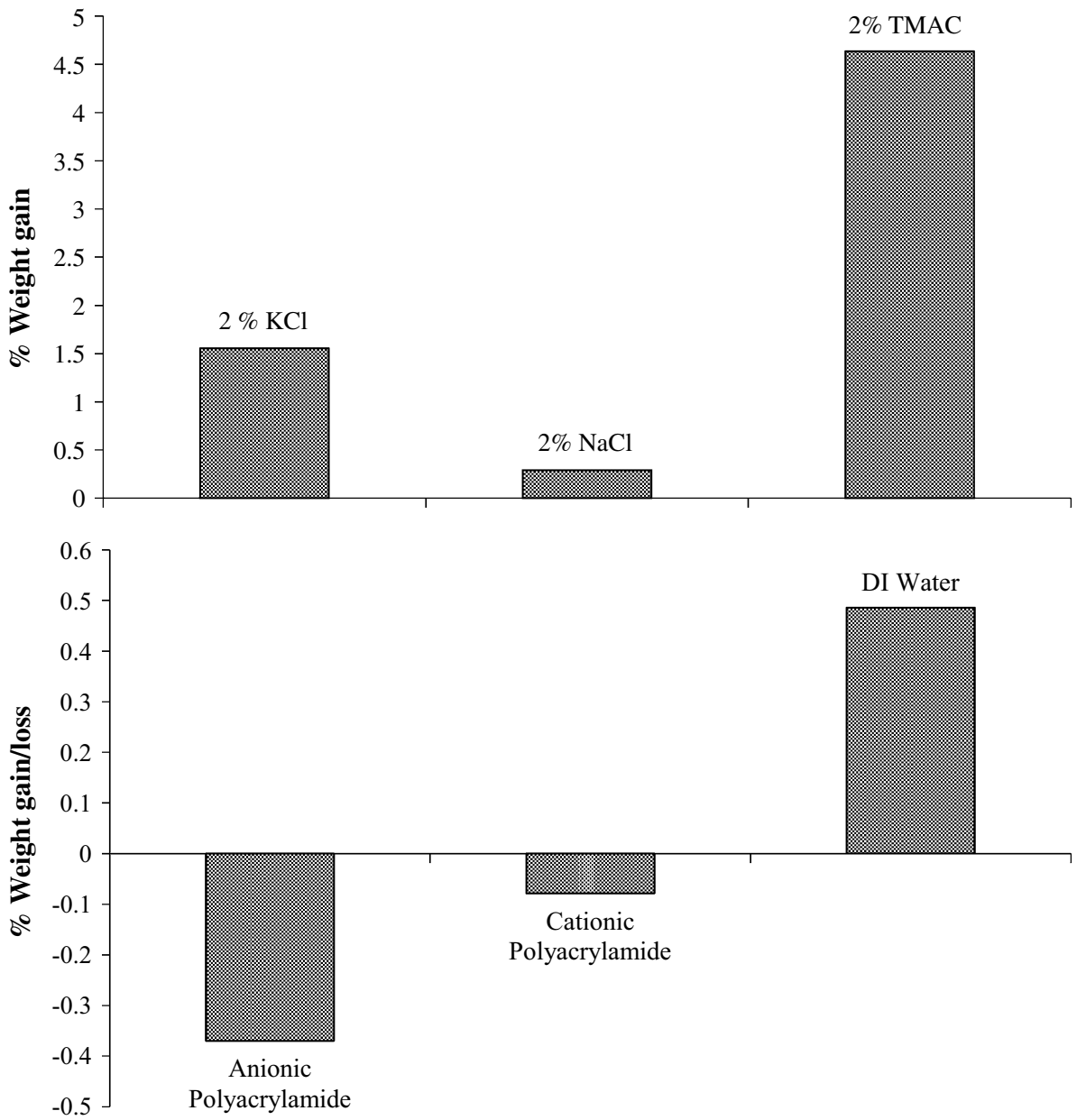
Fig. 16 Percent weight gain of Pride Mountain Formation shale after immersion test

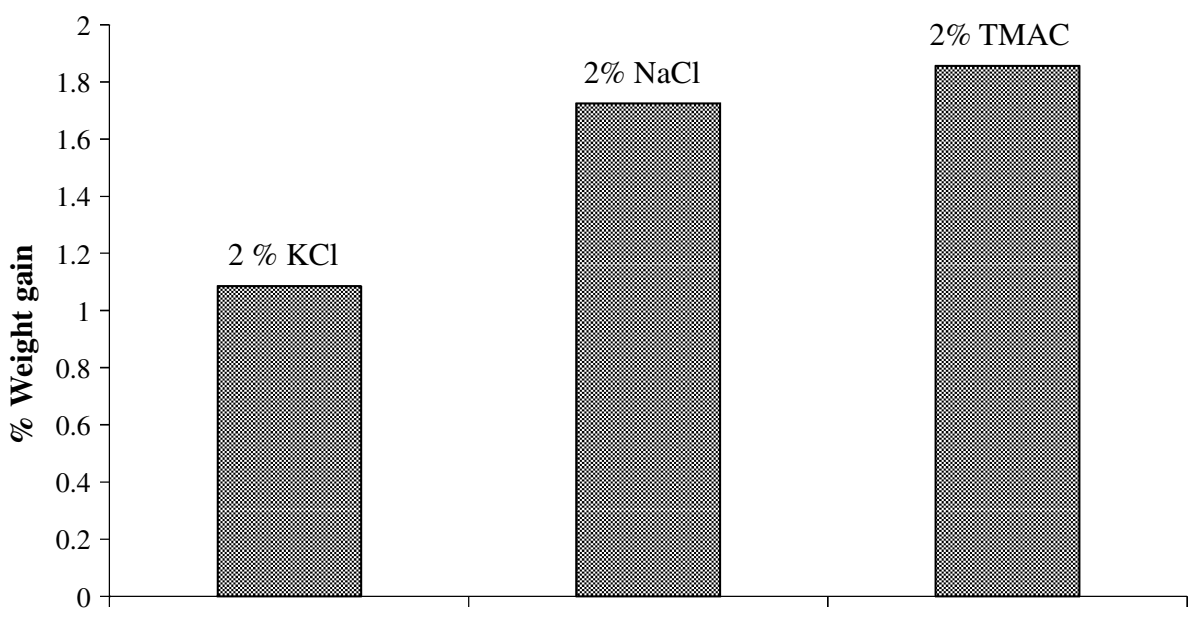

Fig. 17 Percent weight gain of Pride Mountain Formation shale after immersion test

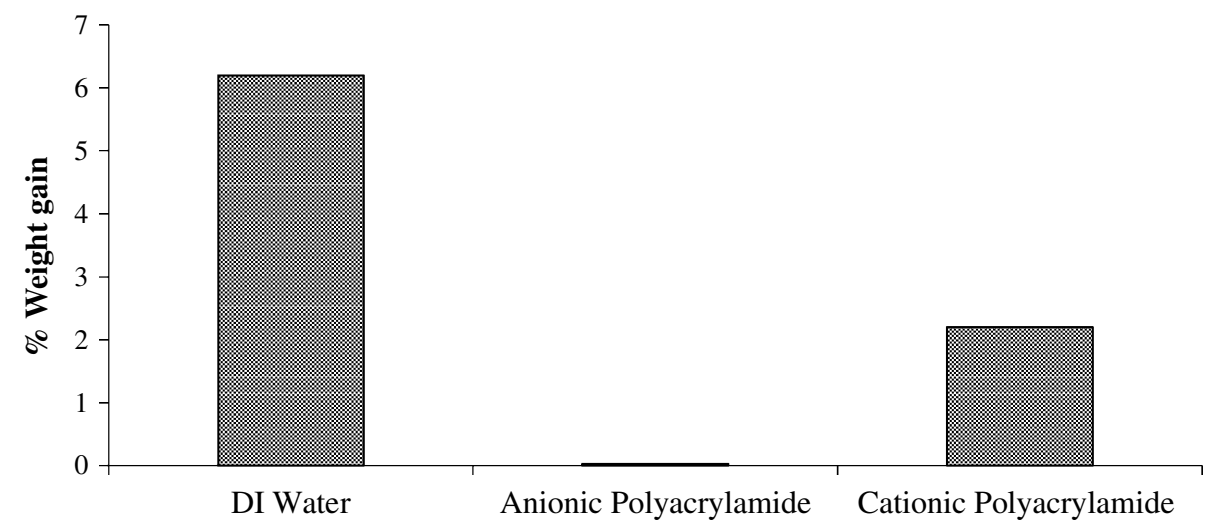

Table 6 Qualitative description of Chattanooga shale samples after immersion tests

\begin{tabular}{ll}
\hline Sample (Pride Mountain) & Qualitative description \\
\hline DI water & Intact/firm \\
$2 \% \mathrm{KCl}$ & Intact/firm \\
$2 \% \mathrm{NaCl}$ & Intact/firm \\
$2 \% \mathrm{TMAC}$ & Intact/soft \\
Anionic polyacrylamide & Intact/firm \\
Cationic polyacrylamide & Intact/firm \\
\hline
\end{tabular}

Table 7 Qualitative description of Pride Mountain Formation shale samples after immersion tests

\begin{tabular}{ll}
\hline Sample (Gorgas) & Qualitative description \\
\hline DI water & Disintegrated \\
$2 \% \mathrm{KCl}$ & Intact/firm \\
$2 \% \mathrm{NaCl}$ & Intact/soft \\
$2 \% \mathrm{TMAC}$ & Intact/firm \\
Anionic polyacrylamide & Intact/firm \\
Cationic polyacrylamide & Intact/firm \\
\hline
\end{tabular}

\section{Rheological studies}

The effect of salts on the rheological properties of the fluid mixtures used in the study is discussed in this section (Figs. 18, 19). Salts were found to be detrimental to the rheology of the fluids containing anionic polymer. The $\mathrm{K}^{+}$ions form a strong bond between the smectite layers in the bentonite, thereby leading to clay aggregates and reduction in the fluid viscosity (Guven et al. 1988). The addition of potassium salts in anionic fluids leads to reduction in viscosity, whereas in cationic fluid systems, salts improve the rheology of the system. This is because apparent viscosity is higher in saline fluids containing cationic polymers. Addition of salt to the cationic polyacrylamide system leads to polyacrylamide-bentonite aggregates that result from the interaction of polyacrylamide with the negative face charge of bentonitic clay. Bentonite is sodium montmorillonite clay, which is major expandable clay in many North American shales. Additionally, the rheological results can be used to correlate the interaction of sodium montmorillonite, with polyacrylamides and salt. Higher apparent viscosity indicates stronger interactions 
Table 8 Application of $\mathrm{KCl}$ based fluids for the shales under study

\begin{tabular}{llll}
\hline Shale & Shale type & $\begin{array}{l}\text { Dispersion limiting abil- } \\
\text { ity of KCl }\end{array}$ & $\begin{array}{l}\text { Swelling limiting abil- } \\
\text { ity of KCl }\end{array}$ \\
\hline Woodford & $\begin{array}{l}\text { Medium hard, high in illite, with expandable clays, Fair } \\
\text { less dispersion shale } \\
\text { gested sug- }\end{array}$ & Good \\
$\begin{array}{l}\text { Chattanooga } \\
\text { Pride Mountain }\end{array}$ & $\begin{array}{l}\text { Hard, high in quartz, less expandable clays } \\
\text { Soft, high expandable, interlayer mixed clays and } \\
\text { highly dispersible }\end{array}$ & Good & Fair \\
\hline
\end{tabular}

Table 9 Application of $\mathrm{NaCl}$ based fluids for studied shale formations

\begin{tabular}{|c|c|c|c|c|}
\hline Shale & Shale type & $\begin{array}{l}\text { Dispersion limiting abil- } \\
\text { ity of } \mathrm{NaCl}\end{array}$ & $\begin{array}{l}\text { Swelling limiting abil- } \\
\text { ity of } \mathrm{NaCl}\end{array}$ & $\begin{array}{l}\text { Is the use of } \\
\mathrm{NaCl} \text { sug- } \\
\text { gested }\end{array}$ \\
\hline Woodford & $\begin{array}{l}\text { Medium hard, high in illite, with expandable } \\
\text { clays, less dispersion shale }\end{array}$ & Good & Fair & Yes \\
\hline Chattanooga & Hard, high in quartz, less expandable clays & Good & Good & Yes \\
\hline Pride Mountain & $\begin{array}{l}\text { Soft, high expandable, interlayer mixed clays and } \\
\text { highly dispersible }\end{array}$ & Fair & Fair & No \\
\hline
\end{tabular}

Table 10 Application of TMAC-based fluids for the studied shale samples

\begin{tabular}{llll}
\hline Shale & Shale type & $\begin{array}{l}\text { Dispersion limiting abil- } \\
\text { ity of TMAC }\end{array}$ & $\begin{array}{l}\text { Swelling limiting ability } \\
\text { of TMAC }\end{array}$ \\
\hline Woodford & $\begin{array}{l}\text { Medium hard, high in illite, with expandable } \\
\text { clays, less dispersion shale } \\
\text { TMAC sug- } \\
\text { gested }\end{array}$ & Fair & Good \\
$\begin{array}{l}\text { Chattanooga } \\
\text { Pride Mountain }\end{array}$ & $\begin{array}{l}\text { Hard, high in quartz, less expandable clays } \\
\text { Soft, high expandable, interlayer mixed clays and } \\
\text { highly dispersible }\end{array}$ & Good & Food \\
\end{tabular}

Fig. 18 Change in apparent viscosity of an anionic polyacrylamide system with shear rate

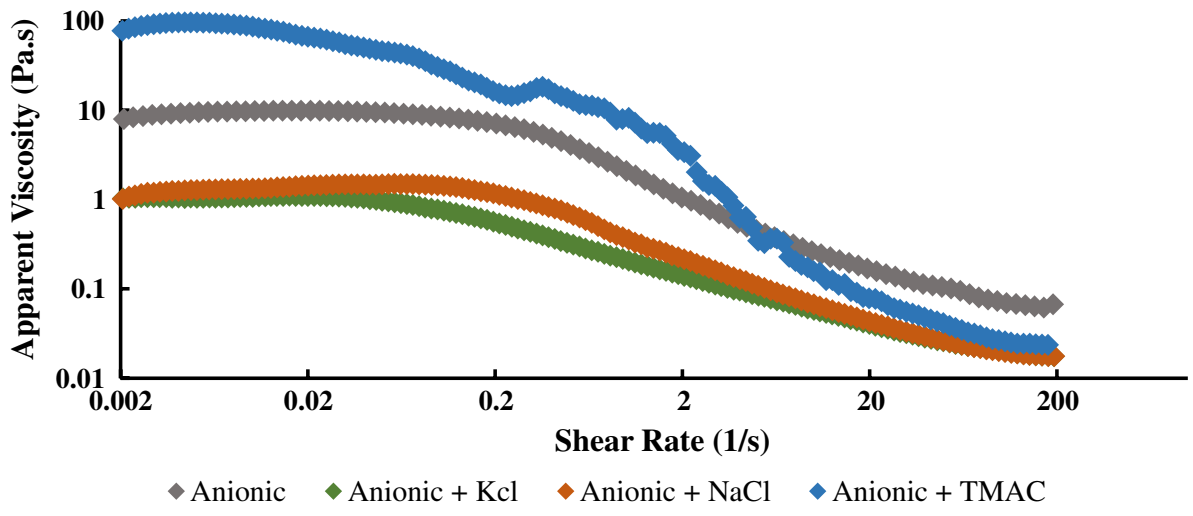

between the clay and the bulk fluid. For both the cationic and anionic polyacrylamide, the viscosity is higher in the presence of TMAC. This corroborates with our immersion tests and SEM results. With TMAC, the bulk fluid adsorbs/ sticks to the shale surface more preventing the water from entering the shale.
The effect of salt on the rheology of bentonite was studied separately (Fig. 20). Bentonite forms an important constituent of the drilling fluid and is used in the production of high density drilling fluids having shear-thinning flow behavior (Goh et al. 2011). Yield stress was determined for the bentonite-salt dispersions. Rheology of bentonite in presence of 
Fig. 19 Change in apparent viscosity of a cationic polyacrylamide system with shear rate

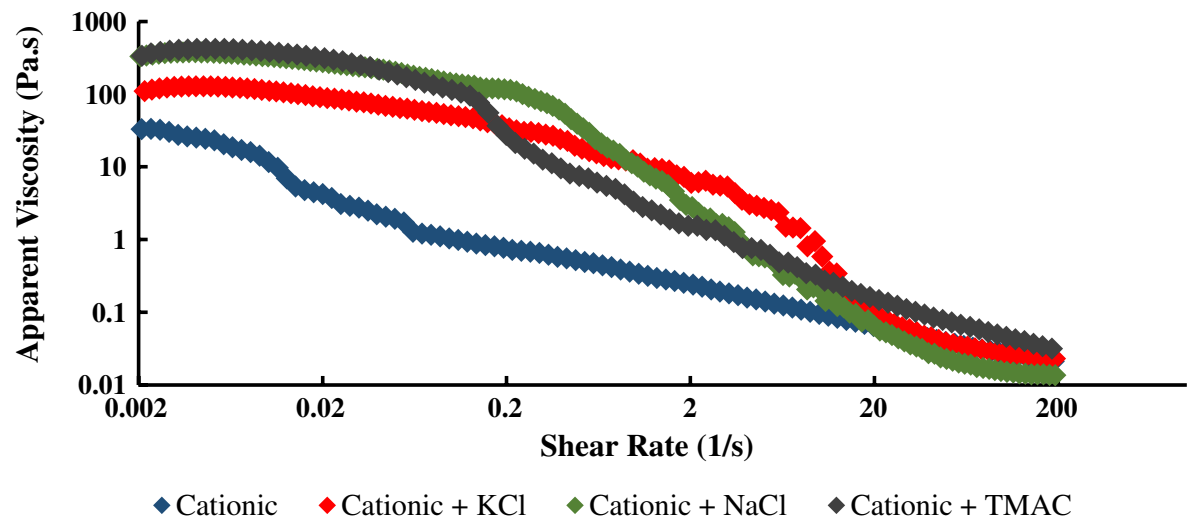

clay-fluid interaction. The following conclusions are drawn from the experimental results

1. Polyacrylamides (anionic and cationic) prevent swelling in all the three shale formations studied by forming an isolation membrane on the shale and preventing the water and ions from entering the shale.

2. Using high concentrations of TMAC is not recommended. TMAC prevents the adsorption of polyacrylamides and also causes excessive shrinkage of shale matrix, which can lead to a loss of mechanical strength in the wellbore.

3. $\mathrm{NaCl}$ increases swelling in montmorillonite-rich shale. Instead, salts like $\mathrm{KCl}$ and TMAC are better inhibitors to use in shale formations rich in expandable clay.

Fig. 20 Change in zero shear-rate viscosity of a bentonite salt system with shear rate

salts and TMAC is indicative of the clay to swell in presence of additives such as salt and TMAC. Addition of $\mathrm{KCl}$ and TMAC leads to a reduction in the yield stress. In the absence of salts, the yield stress of the bentonite increases, due to strong swelling and interparticle interactions between the clay particles. Additionally, this rheological method is easy and reliable in determining the swelling ability of clays in different fluids. The $\mathrm{K}^{+}$and $\mathrm{N}\left(\mathrm{CH}_{3}\right)_{4}^{+}$ions exchange with the more swellable $\mathrm{Na}^{+}$ions in the bentonite, thereby reducing the swelling of the clay, which leads to reduction in the yield stress and the apparent viscosity, whereas, in the presence of $\mathrm{NaCl}$, the swelling is increased due to the larger hydration radius of $\mathrm{Na}^{+}$. Hence, it is recommended for shales rich in expandable clays, such as montmorillonite, to use $\mathrm{KCl}$ instead of $\mathrm{NaCl}$ when formulating fluids.

\section{Conclusions}

In this paper the role of salts, TMAC and polyacrylamides as shale inhibitors are investigated through simple immersion tests and by using rheology as a means of measuring
4. Polyacrylamide with salts and TMAC is very effective in preventing swelling and dispersion of all three shale formations.

5. Salts are inimical to the rheology of polyacrylamides. Salts reduce the viscosity of the fluid system and hence can increase fluid loss.

Acknowledgements We would like to thank the following organizations for partial support of this project: Research Partnership to Secure Energy for America (Contract No. DE-AC26-02NT42677), and Department of Chemical Engineering, Oklahoma State University.

Open Access This article is distributed under the terms of the Creative Commons Attribution 4.0 International License (http://creativeco mmons.org/licenses/by/4.0/), which permits unrestricted use, distribution, and reproduction in any medium, provided you give appropriate credit to the original author(s) and the source, provide a link to the Creative Commons license, and indicate if changes were made.

\section{References}

Al-Bazali T, Zhang J, Chenevert ME, Sharma MM (2008) Factors controlling the compressive strength and acoustic properties of 
shales when interacting with water-based fluids. Int J Rock Mech Min Sci 45(5):729-738

Carman PS, Cawiezel K (2007) Successful breaker optimization for polyacrylamide friction reducers used in slickwater fracturing. Paper presented at the SPE hydraulic fracturing technology conference

Chenevert ME (1970) Shale alteration by water adsorption. J Petrol Technol 22(09):141141-141148

Fink J (2015) Water-based chemicals and technology for drilling, completion, and workover fluids. Gulf Professional Publishing, Houston

Goh R, Leong Y-K, Lehane B (2011) Bentonite slurries-zeta potential, yield stress, adsorbed additive and time-dependent behaviour. Rheol Acta 50(1):29-38

Gomez SL, He W (2012) Fighting wellbore instability: customizing drilling fluids based on laboratory studies of shale-fluid interactions. Paper presented at the IADC/SPE Asia Pacific drilling technology conference and exhibition

Guven N, Panfil DJ, Carney LL (1988) Comparative rheology of waterbased drilling fluids with various clays. Paper presented at the international meeting on petroleum engineering

Habibpour M, Koteeswaran S, Clark PE (2017) Drag reduction behavior of hydrolyzed polyacrylamide/polysaccharide mixed polymer solutions-effect of solution salinity and polymer concentration. Rheol Acta 56(7):683-694. https://doi.org/10.1007/s0039 7-017-1024-1

Himes RE, Simon DE (1990). Fluid additive and method for treatment of subterranean formations. Google Patents

Horsrud P, Bostrom B, Sonstebo EF, Holt RM (1998) Interaction between shale and water-based drilling fluids: laboratory exposure tests give new insight into mechanisms and field consequences of $\mathrm{KCl}$ contents. Paper presented at the SPE annual technical conference and exhibition

Huang H, Azar JJ, Hale AH (1998) Numerical simulation and experimental studies of shale interaction with water-base drilling fluid. Paper presented at the IADC/SPE Asia Pacific drilling technology

Josh M, Esteban L, Delle Piane C, Sarout J, Dewhurst DN, Clennell MB (2012) Laboratory characterisation of shale properties. J Petrol Sci Eng 88:107-124

Khodja M, Canselier JP, Bergaya F, Fourar K, Khodja M, Cohaut N, Benmounah A (2010) Shale problems and water-based drilling fluid optimisation in the Hassi Messaoud Algerian oil field. Appl Clay Sci 49(4):383-393

Koteeswaran S, Pashin JC, Ramsey JD, Clark PE (2017) Quantitative characterization of polyacrylamide-shale interaction under various saline conditions. Petrol Sci 14(3):586-596. https://doi. org/10.1007/s12182-017-0166-1

Lal M (1999) Shale stability: drilling fluid interaction and shale strength. Paper presented at the SPE Asia Pacific oil and gas conference and exhibition, Jakarta, Indonesia

Lu C-F (1988) A new technique for the evaluation of shale stability in the presence of polymeric drilling fluid. SPE Prod Eng 3(03):366-374
Mody FK, Hale AH (1993) Borehole-stability model to couple the mechanics and chemistry of drilling-fluid/shale interactions. J Petrol Technol 45(11):091093-091101

Mody FK, Tare UA, Tan CP, Drummond CJ, Wu B (2002) Development of novel membrane efficient water-based drilling fluids through fundamental understanding of osmotic membrane generation in shales. Paper presented at the SPE annual technical conference and exhibition

Okoro EE, Adewale D (2014) Experimental analysis of shale for 3 evaluating shale drilling fluid 4 interaction in Agbada formation 5. Br J Appl Sci Technol 4(35):4878

Rabe C, da Fontoura SAB, dos Santos Antunes F (2002) Experimental study of interaction shale-fluid through immersion tests. Rev Eng Térmica 1(2):22-28

Rickman R, Mullen MJ, Petre JE, Grieser WV, Kundert D (2008) A practical use of shale petrophysics for stimulation design optimization: all shale plays are not clones of the Barnett shale. Paper presented at the SPE annual technical conference and exhibition

Santos H, Diek A, Da Fontoura S, Roegiers JC (1997) Shale reactivity test: a novel approach to evaluate shale-fluid interaction. Int J Rock Mech Min Sci 34(3):268.e1-268.e11

Steiger RP (1993). Advanced triaxial swelling tests on preserved shale cores. Paper presented at the International journal of rock mechanics and mining sciences and geomechanics abstracts

Tan CP, Richards BG, Rahman SS (1996) Managing physico-chemical wellbore instability in shales with the chemical potential mechanism. Paper presented at the SPE Asia Pacific oil and gas conference

Van Oort E (2003) On the physical and chemical stability of shales. J Petrol Sci Eng 38(3):213-235

Van Oort E, Hale AH, Mody FK (1995) Manipulation of coupled osmotic flows for stabilisation of shales exposed to water-based drilling fluids. Paper presented at the SPE annual technical conference and exhibition

Zhang J, Chenevert ME, Al-Bazali T, Sharma MM (2004) A new gravimetric-swelling test for evaluating water and ion uptake in shales. Paper presented at the SPE annual technical conference and exhibition

Zhou J, Sun H, Stevens RF, Qu Q, Bai B (2011) Bridging the gap between laboratory characterization and field applications of friction reducers. Paper presented at the SPE production and operations symposium

Zhou J, Jung CM, Pedlow JW, Chenevert ME, Sharma MM (2013) A new standardized laboratory protocol to study the interaction of organic-rich shales with drilling and fracturing fluids. Paper presented at the SPE annual technical conference and exhibition

Publisher's Note Springer Nature remains neutral with regard to jurisdictional claims in published maps and institutional affiliations. 